\title{
CARACTERISSTICAS COMPORTAMENTAIS EMPREENDEDORAS E SUA IMPORTÂNCIA NA ATUAÇÃO PROFISSIONAL
}

\section{CHARACTERISTICS OF ENTREPRENEURS AND IT'S IMPORTANCE IN PROFESSIONAL ACTIVITIES}

Débora Regina Schneider Locatelli

Professora do Curso de Administração da Universidade Federal da Fronteira Sul - Campus Erechim

Erechim, RS, Brasil

E-mail: deboraschneider@gmail.com

Marco Antonio Pinheiro da Silveira

Professor do Programa de Pós-Graduação em Administração da Universidade Municipal de São Caetano do Sul -USCS

São Caetano do Sul, SP, Brasil

E-mail: marco.pinheiro@uscs.edu.br

Naira Elizabete Barbacovi

Professora do Instituto de Desenvolvimento Educacional do Alto Uruguai

Getúlio Vargas, RS, Brasil

E-mail: nairabarbacovi28@gmail.com

\section{RESUMO}

O objetivo do estudo foi analisar quais características comportamentais empreendedoras (CCE) são evidenciadas nos estudantes de Engenharia e a importância delas para a atuação profissional. Também buscou-se verificar se há diferença entre gêneros em relação a CCEs; identificar em qual dos grupos de CCEs os acadêmicos estão mais desenvolvidos e por fim comparar as CCEs e as exigências para a atuação profissional dos engenheiros. A pesquisa empregou duas etapas, a primeira quantitativa descritiva, e a segunda qualitativa documental. $\mathrm{O}$ estudo foi realizado com estudantes de Engenharia Ambiental que cursaram a disciplina de Empreendedorismo, em quatro semestres diferentes, somando 132 alunos. A coleta de dados foi realizada utilizando-se $o$ instrumento criado por McClelland. Foram identificadas, no grupo estudado, a presença das CCEs, não havendo diferença significativa entre os gêneros. Concluiu-se que, embora a regulamentação para atuação profissional do engenheiro não traga explicitamente que este deva ser empreendedor, nas entrelinhas das regulamentações isso foi evidenciado.

Palavras-chave: Empreendedor. Regulamentação. Engenharia.

\section{ABSTRACT}

The objective of the study was to analyze which entrepreneurial behavioral characteristics (CCE) are evidenced in Engineering students and their importance for professional performance. We also sought to verify if there is difference between genders in relation to CCEs; To identify in which of the groups of CCEs the academics are more developed and finally to compare the CCEs and the requirements for the professional performance of the engineers. The research used two steps, the first descriptive quantitative, and the second qualitative documentary. The study was carried out with students of Environmental Engineering who studied the discipline of Entrepreneurship, in four different semesters, adding 132 students. The data collection was performed using the instrument created by McClelland. The presence of SCCs was identified in the studied group, with no significant difference between genders. It was concluded that, although the regulations for the professional performance of the engineer do not explicitly state that this should be an entrepreneur, among the lines of regulations this was evidenced.

Keywords Entrepreneur. Regulation. Engineering. 


\section{INTRODUÇÃO}

O empreendedor por muitas vezes foi definido pela palavra competência, ou seja, para ser empreendedor tinha que ter competência, e essa era desmembrada em características como habilidades, conhecimento e atitudes. No entanto, verificam-se outros aspectos importantes para que as pessoas desenvolvam características empreendedoras, dentre esses, tem-se questões como: educação, formação, experiências, influências familiares, culturais, dentre outros. Além disso, há evidências empíricas que verificam que os traços de personalidade são importantes para descrever o auto-emprego e o empreendedorismo (CALIENDO; FOSSEN; KRITIKOS, 2014). Para Lee, Shim e Lee (2016) é um conjunto de aspectos que define a capacidade empreendedora.

Segundo Holienka, Holienková e Gál (2015), a educação voltada para o empreendedorismo e o incentivo no desenvolvimento empresarial dos estudantes, com visão de futuro é de responsabilidade das escolas e universidades. Isto é, as instituições de ensino devem ter como objetivo aumentar a criatividade, inovação e capacidade de identificar oportunidades e executar ideias, despertando nos alunos a "mentalidade empreendedora" que pode ser realizada em diferentes atividades. Assim, os desafios para a educação do empreendedorismo estão definidos e as universidades têm papel importante no desenvolvimento de seus alunos.

É importante ressaltar que a inserção do empreendedorismo nas matrizes curriculares nos mais diversos cursos têm crescido nos últimos anos, visto que o desenvolvimento de características comportamentais empreendedoras mostra o quanto os acadêmicos são criativos, possuem iniciativa e capacidade de planejamento. Valendo-se da importância deste tema, este estudo tem como questão de pesquisa: Quais as características comportamentais empreendedoras (CCEs) são mais evidentes nos estudantes do curso de Engenharia em relação sua atuação profissional? Dessa forma, o estudo teve como objetivo geral analisar quais CCEs são evidenciadas nos estudantes de Engenharia e a importância delas para a atuação profissional. Mais especificamente buscou-se verificar se há diferença entre gêneros em relação às CCEs ${ }^{1}$; identificar em qual dos grupos de CCEs os acadêmicos estão mais desenvolvidos ${ }^{2}$ e por fim comparar as CCEs e as exigências para a atuação profissional dos engenheiros ${ }^{3}$.

Vale ressaltar a importância do estudo, o qual busca averiguar se as exigências para a atuação do engenheiro evidenciam as CCEs, visto que, de acordo com a literatura fica cada vez mais notório que as características empreendedoras devem estar evidenciadas em qualquer profissão, principalmente para os profissionais que visam o sucesso profissional num mundo tão competitivo.

Na sequência são apresentados o referencial teórico, os procedimentos metodológicos, os resultados e discussões e as conclusões. 


\section{REFERENCIAL TEÓRICO}

\section{Empreendedor e as características comportamentais empreendedoras}

Filion (1999), utilizando-se da ideia de Schumpeter, declara que o cerne do empreendedorismo está na percepção e no aproveitamento de oportunidades de negócios. Dolabela (2008), por sua vez, defende que o empreendedor é aquele que sonha e faz de tudo para transformar seu em realidade, usa o inconformismo para fazer descobertas e propor coisas positivas para si e para os outros. Busca caminhos não percorridos, acredita que pode mudar o mundo, quer ser o protagonista e autor de sua história e do ambiente onde vive. Ter uma empresa é só uma das formas de empreender, assim, o empreendedor pode estar nas mais diversas áreas: educação, medicina, pesquisa, direito, arquitetura, engenharia, serviço social, distribuição, artes e órgãos públicos (DOLABELA, 2008; HISRICH; PETERS; SHEPHERD, 2009).

O interesse pelo tema empreendedorismo iniciou com uma abordagem econômica e depois comportamentalista, visando entender o empreendedor como pessoa. Nesta linha comportamental pode ser citado como precursor Weber, mas o principal destaque foi David McClelland (DIAS; SOUZA NETO; BOAS, 2010), a partir da década de 50, com o estudo da ascensão e declínio das civilizações. A descoberta mais relevante dele foi quanto à necessidade de realização, a qual foi a base do estudo com os empreendedores (FILION, 1999).

Com o resultado de seus estudos, McClelland desenvolveu a teoria das características comportamentais empreendedoras (CCEs), composta por dez características divididas em três categorias (McCLELLAND, 1972):

a) Realização:

- Busca de oportunidades e iniciativa: faz as coisas antes de solicitado ou das circunstâncias, age para expandir o negócio à novas áreas e aproveita oportunidades fora do comum;

- Correr riscos calculados: avalia alternativa e calcula riscos deliberadamente, age para reduzir os riscos ou controlar os resultados e coloca-se em situações desafiantes ou riscos moderados;

- Persistência: age diante de um obstáculo, muda de estratégia a fim de enfrentar um desafio e faz sacrifício pessoal ou desenvolve um esforço extraordinário para completar uma tarefa;

- Exigência de qualidade e eficiência: encontra maneiras de fazer as coisas melhor, mais rápido ou mais barato; age para satisfazer os outros ou exceder os padrões e desenvolve ou utiliza procedimentos para assegurar que o trabalho seja entregue a tempo;

- Comprometimento: assume responsabilidade pessoal pelo desempenho para atingir metas e objetivos; colabora com os empregados ou se coloca no lugar deles, esmera-se em manter os clientes satisfeitos e coloca em primeiro lugar a boa vontade a longo prazo, acima do lucro a curto prazo.

b) Planejamento:

- Busca de informações: dedica-se pessoalmente na obtenção de informações, investiga coisas necessária para realizar o que deseja e consulta especialista para obter assessoramento;

- Estabelecimento de metas: estabelece metas e objetivos que são desafiantes e com significado pessoal, claros, específicos, de curto e longo prazo; 
- Planejamento e monitoramento sistemáticos: planeja dividindo tarefas e subtarefas com prazos definidos; constantemente revisa seus planos, mantém registros financeiros e utiliza-os para tomar decisões.

c) Poder:

- Persuasão e redes de contato: utiliza estratégias deliberadas para influenciar ou persuadir os outros; utiliza pessoas-chave para atingir objetivos, age para desenvolver e manter relações comerciais;

- Independência e autoconfiança: busca autonomia em relação a normas e controles de outros; mantém seu ponto de vista mesmo com oposição ou com resultados desanimadores; expressa confiança para completar uma tarefa difícil ou para enfrentar um desafio.

Dentre os três grupos McClelland (1972) aponta que a necessidade de realização é a mais forte. Segundo ele, esta é a primeira a ser identificada entre os empreendedores bem-sucedidos e, as pessoas que buscam realização, procuram mudanças em suas vidas e buscam formas para realizá-las.

Graças aos estudos comportamentalistas é possível descrever se uma pessoa tem ou não as características e aptidões mais comumente encontradas em empreendedores de sucesso, porém não foi possível estabelecer um perfil psicológico absolutamente científico do empreendedor (FILION, 1999).

McClelland desenvolveu um questionário para identificar estas características nas pessoas, este é um dos mais utilizados para se estudar as CCEs (CAMARGO, 2005). Este instrumento é utilizado como base para o Programa das Nações Unidas para o Desenvolvimento (PNUD), o qual realiza desde 1988 capacitação de empreendedores, e também pelo Serviço Brasileiro de Apoio às Micro e Pequenas Empresas (Sebrae) como instrumento de auto-avaliação do Empretec (DIAS; SOUZA NETO; BOAS, 2010).

\section{Atuação Profissional}

A atuação dos profissionais de qualquer área segue uma série de regulamentações estabelecidas pelos órgãos oficias que regulamentam além de todos os cursos de graduação, os órgãos de classe.

A Resolução n 48 do Conselho Federal de Educação de 27 de abril de 1976, fixa os conteúdos mínimos, a duração das graduações em Engenharia e define suas áreas de habilitação. Esta regulamentação cita que o currículo dos cursos de engenharia deve conter além da formação técnica, conteúdos que cubram as áreas de Humanidade e de Ciências Sociais, destacando-se Administração e Economia e Ciências do Ambiente (Parágrafo único do artigo $4^{\circ}$ ). Mostrando assim que o profissional engenheiro deverá ter também, para a sua atuação profissional, aspectos humanos e sociais.

A Lei de Diretrizes de Bases da Educação (LDB) fez surgir o Plano Nacional de Educação (PNE), Lei no 10.172, de 9 de janeiro de 2001 (BRASIL, 2001), e esta trouxe as Diretrizes Curriculares Nacionais (DCNs). Assim, qualquer curso superior deve seguir estas leis e diretrizes. A partir destes, surgem os pareceres técnicos, abordando os mais diversos assuntos relacionados aos cursos de graduação existentes no Brasil. O Parecer n. ${ }^{0} 1.362$, de 12 de dezembro de 2001 estabelece novos currículos para os cursos de graduação em engenharia e indica que estes sejam flexíveis, para que o profissional formado tenha opções de áreas de conhecimento e atuação, ligação com o campo de atuação do profissional, embasamento filosófico para competência, educação voltada para o aluno, ênfase na síntese e na transdisciplinaridade, preocupação com 
a valorização do ser humano e preservação do meio ambiente, integração social e política do profissional, possibilidade de articulação direta com a pós-graduação e forte vinculação entre teoria e prática.

Já a Resolução $n^{\circ} 11$, do Conselho Nacional de Educação por intermédio da Câmara de Educação Superior, de 11 de março de 2002 aconselha que os cursos de engenharia formem profissionais

[...] generalista, humanista, crítica e reflexiva, capacitado a absorver e desenvolver novas tecnologias, estimulando a sua atuação crítica e criativa na identificação e resolução de problemas, considerando seus aspectos políticos, econômicos, sociais, ambientais e culturais, com visão ética e humanística, em atendimento às demandas da sociedade.

A Resolução $n^{\circ} 11$ define ainda que a estrutura dos cursos de engenharia deve ter três núcleos de conhecimentos, sem citar as disciplinas a serem ministradas: básicos com $30 \%$ da carga horária mínima, profissionalizantes com $15 \%$ da carga horária mínima e específicos com o restante de carga horária do curso. Fora estes núcleos de conhecimentos há necessidade de, no mínimo, 160 horas de estágios curriculares e a realização de trabalho de conclusão de curso. Também indica que a formação do engenheiro tem por objetivo dotar o profissional dos conhecimentos requeridos para o exercício das seguintes competências e habilidades gerais: aplicar conhecimentos matemáticos, científicos, tecnológicos e instrumentais à engenharia; projetar e conduzir experimentos e interpretar resultados; conceber, projetar e analisar sistemas, produtos e processos; planejar, supervisionar, elaborar e coordenar projetos e serviços de engenharia; identificar, formular e resolver problemas de engenharia; desenvolver e/ou utilizar novas ferramentas e técnicas; supervisionar a operação e a manutenção de sistemas; avaliar criticamente a operação e a manutenção de sistemas; comunicar-se eficientemente nas formas escrita, oral e gráfica; atuar em equipes multidisciplinares; compreender e aplicar a ética e responsabilidade profissionais; avaliar o impacto das atividades da engenharia no contexto social e ambiental; avaliar a viabilidade econômica de projetos de engenharia; assumir a postura de permanente busca de atualização profissional.

A Lei $n^{\circ} 5.194$, de 24 de dezembro de 1966 (BRASIL, 1966), regula o exercício das profissões de Engenheiro, Arquiteto e Engenheiro-Agrônomo, e dá outras providências. A Resolução $n^{\circ} 447$ do Conselho Federal de Engenharia e Agronomia (CREA), de 22 de setembro de 2000, define as atribuições do Engenheiro Ambiental como sendo "[...] desempenho das atividades 1 a 14 e 18 do art. $1^{\circ}$ da Resolução $n^{\circ} 218$, de 29 de junho de 1973, referentes à administração, gestão e ordenamentos ambientais e ao monitoramento e mitigação de impactos ambientais, seus serviços afins e correlatos". As atividades descritas na Resolução $n^{\circ}$ 218 do CREA, citada anteriormente são: supervisão, coordenação e orientação técnica; estudo, planejamento, projeto e especificação; estudo de viabilidade técnico-econômica; assistência, assessoria e consultoria; direção de obra e serviço técnico; vistoria, perícia, avaliação, arbitramento, laudo e parecer técnico; desempenho de cargo e função técnica; ensino, pesquisa, análise, experimentação, ensaio e divulgação técnica; extensão; elaboração de orçamento; padronização, mensuração e controle de qualidade; execução de obra e serviço técnico; fiscalização de obra e serviço técnico; produção técnica e especializada; condução de trabalho técnico e execução de desenho técnico.

Machado (2009) ressalta que as atribuições do engenheiro ambiental tratadas na legislação são genéricas, pois os currículos dos cursos de Engenharia Ambiental são muito diferentes entre os cursos 
oferecidos no Brasil. Ela continua afirmando que a Lei $n^{\circ}$ 5194/66, aponta que o profissional só pode exercer legalmente a sua profissão após o registro no Conselho Regional, o curso superior somente o capacita.

O profissional pode solicitar junto ao CREA, conforme disposto no Artigo $3^{\circ}$ da Resolução n ${ }^{\circ} 447 / 2000$ extensões de atribuições. Para tanto, o profissional faz uma solicitação que é analisada pelas câmaras especializadas (MACHADO, 2009). Após o ano 2000, já foram realizadas quatro decisões plenárias:

a) PL 0979/2002: os engenheiros ambientais podem desenvolver atividades de monitoramento da fauna aquática e terrestre, da flora e do meio físico nas áreas impactadas;

b) PL 3723/2003: salienta que para se responsabilizar tecnicamente pelo Gerenciamento de Resíduos Químicos da área da saúde, o profissional deverá comprovar que cursou disciplinas da área da química;

c) PL 0464/2007: atribuições para atividade de obras de terras e contenções, desde que tenham conhecimento sobre mecânica dos solos, fundações, resistência dos materiais, sistemas estruturais, construção civil, dentre outros;

d) PL 1701/2008: reforça o descrito na PL 3723, decidindo que o Profissional Engenheiro Ambiental em questão, não possui atribuição para Gerenciamento de Resíduos de serviços da área da saúde, pois ficou constatada a escassez de conteúdos formativos que habilitem para tal atividade.

Há também a Resolução do CONFEA no 1.010, de 22 de agosto de 2005, a qual regulamenta as atribuições de títulos profissionais, atividades, competências e caracterização do âmbito de atuação dos profissionais inseridos no Sistema CONFEA/CREA, para efeito de fiscalização do exercício profissional.

\section{PROCEDIMENTOS METODOLÓGICOS}

A pesquisa foi realizada em duas etapas. A primeira etapa quantitativa e descritiva, tendo a coleta de dados através de questionário. Classifica-se como quantitativa por utilizar a quantificação tanto na coleta de dados quanto no tratamento destes, por meio de técnicas estatísticas descritivas e frequências absoluta e percentual. Muito utilizada por ter a intenção de avalizar a exatidão dos resultados, com menores distorções de análise e interpretação, o que proporciona mais segurança ao pesquisador nas inferências (RICHARDSON et al., 2008). A pesquisa descritiva, por sua vez, visa investigar uma situação específica, podendo esta envolver um grupo ou um indivíduo (RICHARDSON et al., 2008; GIL, 2008).

A coleta de dados foi realizada utilizando-se o questionário de David McClelland (1972) para mensurar as características comportamentais empreendedoras (CCEs), "[...] em razão da experiência do autor sobre o assunto empreendedorismo e pela grande utilização deste instrumento de coleta de dados em estudos científicos já publicados" (CAMARGO, 2005, p. 77).

O questionário é formado por cinquenta e cinco afirmativas, em cada uma delas o comportamento do respondente é expresso considerando pontuação 1, equivalente a "nunca" ter tal comportamento, 2 "raras vezes", 3 "algumas vezes", 4 "usualmente" e 5 "sempre" ter este comportamento. O respondente é orientado a considerar como ele é no momento em que está respondendo e não como gostaria de ser. Essas entre outras orientações são apresentadas no cabeçalho de questionário. Junto com a criação do questionário e de sua forma de avaliação, McClelland elaborou uma tabela com fatores de correção, para que não ocorra a supervalorização das CCEs no preenchimento. Este fator é aplicado quando na soma das questões 11, 22, 
33 , 44 e 55 , os valores ficarem de 20 a 25 , sendo que de 20 a 21 é subtraído 3 pontos em todas as outras somas, de 22 a 23 é subtraído 5 e de 24 a 25,7 pontos.

McClelland (1972) apontou que, como as questões do instrumento são subjetivas, elas refletem o momento em que se encontra o respondente, no caso desse estudo, os acadêmicos estão em sua primeira semana de aula do semestre.

A aplicação foi manual com o questionário impresso, quem deixava uma das afirmativas em branco era orientado a preenchê-la para que nenhum questionário fosse descartado. Cada respondente recebeu o seu resultado por e-mail e os dados das turmas foram apresentados na aula subsequente, junto com as explicações sobre a metodologia e as características comportamentais empreendedoras.

Para Camargo (2005, p. 82), o questionário desenvolvido por McClelland apresenta como vantagens: identificar características do perfil empreendedor, ter tabela de autocorreção e de mapas, permite comparação e facilita a identificação. Ainda, segundo o autor, esse questionário quando desenvolvido foi idealizado para os Estados Unidos na década de 1970, sendo considerado um questionário extenso. No entanto, esses fatores, não impedem sua reaplicação em outras realidades.

Após a aplicação, os dados foram inseridos em uma planilha de cálculo, nela foram feitos os cálculos básicos, outros foram realizados com auxílio do software estatístico Statistical Package for the Social Sciences (IBM SPSS).

O estudo foi realizado em uma universidade federal com acadêmicos do curso de Engenharia Ambiental que cursaram a disciplina de Empreendedorismo, oferecida no $9^{\circ}$ período do curso. Foram coletados os dados no primeiro dia de aula da disciplina no segundo semestre de 2014, no primeiro e no segundo semestre de 2015 e no segundo semestre de 2016. Foram coletados os dados com todos os acadêmicos que estavam cursando a disciplina nos referidos semestres, compondo assim a população do estudo: A pesquisa dessa forma caracteriza-se como censo. A Tabela 1, apresenta a população em estudo.

Tabela 1. Identificação da população

\begin{tabular}{ccc}
\hline Ano-Semestre & Quantidade de acadêmicos respondentes & Percentual \\
\hline $2014-2$ & 37 & 28,0 \\
$2015-1$ & 48 & 36,4 \\
$2015-2$ & 22 & 16,7 \\
$2016-2$ & 25 & 18,9 \\
\hline Total & $\mathbf{1 3 2}$ & $\mathbf{1 0 0 , 0}$ \\
\hline
\end{tabular}

Fonte: Dados da pesquisa.

A segunda etapa foi qualitativa e documental. A pesquisa qualitativa propicia o aprofundamento no fenômeno estudado (RICHARDSON et al., 2008; GIL, 2008), suas relações, buscando manter aberta a análise para perceber a individualidade dos fatos e ao mesmo tempo seus múltiplos significados (GIL, 2008). A pesquisa documental utiliza-se de materiais que não receberam até agora análise, ou também que podem ser analisados de outra forma, tendo como base os objetivos da pesquisa, possibilita dados suficientes sem a necessidade de pesquisa de campo, pode se utilizar de várias fontes de documentação (GIL, 2008). Nesse estudo foram utilizados documentos escritos de vários órgãos que regulamentam os cursos e atividade profissional dos engenheiros. 
A análise dos dados ao final da coleta foi feita utilizando-se de análise de conteúdo, como indicado por Gil (2002), pois se tem grande quantidade de materiais produzidos. Bardin (2004) indica que a análise de conteúdo seja realizada em três etapas: a) pré-análise: é realizada a escolha dos documentos e a preparação destes para análise; b) descrição analítica: estudo aprofundado orientado pelos objetivos do estudo e pela literatura, também se faz os procedimentos de codificação, categorização e classificação dos dados, particularmente nesse estudo foi realizada comparação das CCEs e da atuação profissional do engenheiro; c) interpretação referencial: estabelecimento das relações entre os dados, aprofundamento da análise e até chegar aos resultados concretos da pesquisa, conforme problemática levantada inicialmente.

\section{RESULTADOS E DISCUSSÕES}

A apresentação dos dados ocorreu de forma a responder aos objetivos específicos propostos. Assim, primeiramente é verificado se há diferença entre gêneros em relação à CCEs. Como resultado, constatou-se que 72 discentes, ou seja, um total de $54,5 \%$ das respondentes era do sexo feminino, representando a maior parte da amostra. Com relação à quantidade de estudantes por semestre letivo, constata-se que o semestre 2015.1 foi o que apresentou maior número de alunos, essas informações estão evidenciadas conforme Tabela 2. Já em relação aos alunos do sexo masculino, é possível verificar que o semestre 2016.2 foi o semestre que houve maior representação masculina perante aos demais semestres estudados.

Tabela 2. Distribuição de gênero por semestre

\begin{tabular}{|c|c|c|c|c|c|c|c|c|c|}
\hline \multirow{3}{*}{$\begin{array}{c}\text { Sexo } \\
\text { Feminino }\end{array}$} & \multicolumn{8}{|c|}{ Ano-Semestre } & \multirow{3}{*}{$\begin{array}{r}\text { Tota } \\
72\end{array}$} \\
\hline & \multicolumn{2}{|c|}{ 2014-2 } & \multicolumn{2}{|c|}{ 2015-1 } & \multicolumn{2}{|c|}{ 2015-2 } & \multicolumn{2}{|c|}{ 2016-2 } & \\
\hline & 20 & $54,1 \%$ & 29 & $60,4 \%$ & 17 & $77,3 \%$ & 6 & $24 \%$ & \\
\hline Masculino & 17 & $45,9 \%$ & 19 & $39,6 \%$ & 5 & $22,7 \%$ & 19 & $76 \%$ & 60 \\
\hline Total & 37 & $100 \%$ & 48 & $100 \%$ & 22 & $100 \%$ & 25 & $100 \%$ & 132 \\
\hline
\end{tabular}

Fonte: Dados da pesquisa.

A Tabela 3 apresenta os dados de cada uma das CCEs com relação os gêneros em cada semestre pesquisado.

Tabela 3. CCEs de cada gênero por semestre.

\begin{tabular}{|c|c|c|c|c|c|c|c|c|c|}
\hline \multirow{2}{*}{ CCEs } & \multirow{2}{*}{ Média McClelland } & \multicolumn{2}{|c|}{2014.2} & \multicolumn{2}{|c|}{2015.1} & \multicolumn{2}{|c|}{2015.2} & \multicolumn{2}{|c|}{2016.2} \\
\hline & & $\mathbf{F}$ & M & $\mathbf{F}$ & M & $\mathbf{F}$ & $\mathbf{M}$ & $\mathbf{F}$ & M \\
\hline Busca de oportunidades & 15 & 18 & 17 & 18 & 17 & 17 & 17 & 17 & 17 \\
\hline Persistência & 15 & 18 & 17 & 16 & 16 & 17 & 17 & 16 & 16 \\
\hline Comprometimento & 15 & 20 & 19 & 19 & 18 & 20 & 18 & 19 & 19 \\
\hline Exigência de qualidade & 15 & 17 & 17 & 18 & 17 & 17 & 17 & 18 & 17 \\
\hline Correr riscos calculados & 15 & 16 & 16 & 16 & 16 & 16 & 16 & 16 & 16 \\
\hline Estabelecimento de metas & 15 & 19 & 19 & 20 & 19 & 20 & 19 & 19 & 19 \\
\hline Busca de informações & 15 & 19 & 18 & 19 & 18 & 19 & 19 & 21 & 19 \\
\hline Planejamento & 15 & 17 & 17 & 17 & 16 & 17 & 17 & 17 & 18 \\
\hline Persuasão & 15 & 15 & 15 & 17 & 15 & 16 & 17 & 16 & 16 \\
\hline Independência & 15 & 17 & 18 & 18 & 17 & 17 & 18 & 16 & 16 \\
\hline
\end{tabular}

Fonte: Dados da pesquisa. 
Conforme Tabela 3, não há diferença significativa entre os gêneros. Na turma 2015.1 há uma pequena vantagem das estudantes, em oito das dez CCEs, ficando empatados em persistência e correr riscos calculados. Esta similaridade dos gêneros é positiva, pois se verifica assim que, pelo menos nas turmas estudadas, a formação acadêmica preserva a igualdade de gênero, espera-se que na atuação profissional, resultado dessa formação também haja igualdade de gênero.

O segundo objetivo específico era identificar em qual dos grupos de CCEs os acadêmicos estão mais desenvolvidos. A Tabela 4 mostra que em todas as CCEs os acadêmicos estão acima dos 15 pontos que são indicados por McClelland (1972) como o mínimo para determinar que a pessoa tenha aquela CCE desenvolvida.

Tabela 4. Média das CCEs por semestre

\begin{tabular}{|c|c|c|c|c|c|c|}
\hline & CCEs & Média McClelland & 2014.2 & 2015.1 & 2015.2 & 2016.2 \\
\hline \multirow{6}{*}{ 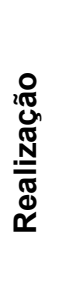 } & Busca de oportunidades & 15 & 17 & 17 & 17 & 16 \\
\hline & Persistência & 15 & 17 & 16 & 17 & 15 \\
\hline & Comprometimento & 15 & 19 & 19 & 20 & 19 \\
\hline & Exigência de qualidade & 15 & 17 & 17 & 17 & 16 \\
\hline & Correr riscos calculados & 15 & 16 & 16 & 16 & 16 \\
\hline & Média da categoria & - & 17,2 & 17 & 17,4 & 16,4 \\
\hline \multirow{4}{*}{ 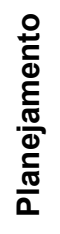 } & Estabelecimento de metas & 15 & 19 & 19 & 19 & 18 \\
\hline & Busca de informações & 15 & 19 & 18 & 19 & 19 \\
\hline & Planejamento & 15 & 17 & 17 & 17 & 17 \\
\hline & Média da categoria & - & 18,3 & 18,0 & 18,3 & 18,0 \\
\hline \multirow{3}{*}{$\begin{array}{l}\frac{1}{0} \\
\frac{0}{0} \\
0\end{array}$} & Persuasão & 15 & 15 & 16 & 16 & 15 \\
\hline & Independência & 15 & 17 & 17 & 18 & 16 \\
\hline & Média da categoria & - & 16 & 16,5 & 17 & 15,5 \\
\hline
\end{tabular}

Fonte: Dados da pesquisa.

Verifica-se que os dados das quatro turmas pesquisadas não apresentam diferenças significativas de um semestre para o outro dentro de cada característica. Os quatro grupos pesquisados não apresentam uma característica que se sobressaia muito perante as demais, as que ficaram com maior pontuação foram: comprometimento, estabelecimento de metas e busca de informações, as duas últimas que fazem parte da categoria Planejamento. Com menor pontuação, porém sem ainda ficar abaixo dos quinze pontos estabelecidos por McClelland (1972) como mínimo, foram persuasão e correr riscos calculados, sendo as duas da categoria Realização. Observou-se que não há nenhuma que tenha pontuação próxima ao máximo que é 25 pontos.

Analisando as três categorias que agrupam estas CCEs, a que apresenta a maior média é a de Planejamento, em todos os semestres pesquisados. Fazendo uma análise descritiva destes dados, apresentados na Tabela 5, verifica-se que mesmo a média não tendo variação significativa, pode ser observado que os valores de mínimo e máximo têm variação de até 17 pontos, o que é significativo e demonstra que há alguns estudantes que ainda não conseguem atingir o mínimo em algumas CCEs. A que ficou com maior variação foi busca de informações, seguida de exigência de qualidade, demonstrando que 
não há uniformidade nos perfis dos estudantes. As que ficaram com menos distância entre mínimo e máximo foram correr riscos calculados (11 pontos), seguida de planejamento e persuasão.

Tabela 5. Descrição dos dados

\begin{tabular}{lccccc}
\hline CCE & $\begin{array}{c}\text { Tamanho da } \\
\text { Amostra }\end{array}$ & Mínimo & Máximo & Média & Desvio padrão \\
\hline G1 Busca de oportunidades & 132 & 10,00 & 24,00 & 17,2652 & 2,77629 \\
G2 Persistência & 132 & 10,00 & 23,00 & 16,7121 & 2,35586 \\
G3 Comprometimento & 132 & 11,00 & 25,00 & 19,0833 & 2,67028 \\
G4 Exigência de qualidade & 132 & 10,00 & 25,00 & 17,3409 & 3,02617 \\
G5 Correr riscos calculados & 132 & 11,00 & 22,00 & 16,1212 & 2,16858 \\
G6 Estabelecimento de metas & 132 & 11,00 & 25,00 & 19,3485 & 3,07907 \\
G7 Busca de informações & 132 & 8,00 & 25,00 & 18,8485 & 2,78075 \\
G8 Planejamento & 132 & 11,00 & 23,00 & 17,2803 & 2,63365 \\
G9 Persuasão & 132 & 9,00 & 21,00 & 15,8258 & 2,47583 \\
G10 Independência & 132 & 11,00 & 24,00 & 17,3333 & 2,48865 \\
\hline
\end{tabular}

Fonte: Dados da pesquisa.

A Tabela 6 mostra a frequência e o percentual cumulativo que compreende cada soma de ponto em cada uma das CCEs. Duas CCEs se destacam: comprometimento e busca de informações, pois a primeira tem $90,9 \%$ dos respondentes acima dos 15 pontos indicados como mínimo necessário para se ter esta característica desenvolvida. A segunda, busca de informações, 90,2\% acima de 15 pontos. Estabelecimento de metas também ficou com um percentual alto, 88,6\% acima de 15 pontos. A persuasão foi a que ficou com menor percentual acima de 15 pontos $58,3 \%$, seguida por correr riscos calculados que ficou com $62,1 \%$ acima do mínimo. Estes dados são importantes tendo que a média por vezes não oferece tanto significado, quanto se analisar os dados de forma fragmentada. A análise destas informações reforça que a categoria mais desenvolvida é a de Planejamento e menos desenvolvida é a de Poder.

Por fim, realizou-se a comparação das CCEs e exigências para a atuação profissional dos engenheiros. Utilizou-se como categorias de análise as próprias CCEs, que muito embora não foram encontradas de forma literal nas regulamentações de atuação profissional dos engenheiros, se buscou nas entrelinhas o entendimento de como estas se relacionavam com as CCEs. Embora subjetivo, foi um trabalho de interpretação e busca de como aquilo foi pensado pelos responsáveis por criar estes regulamentos, foi enriquecedor para os pesquisadores, num pensamento da construção da profissão ao longo do tempo.

Analisando-se as regulamentações que apresentam as exigências para a atuação do profissional engenheiro, verificou-se que a Resolução $n^{\circ} 48, C F E / 1976$, parágrafo único do artigo $4^{\circ}$, indica que se tenham matérias de formação geral em Humanidade e de Ciências Sociais, o que pode indicar que o profissional da área de engenharia buscaria assim o estabelecimento de metas, o planejamento e monitoramento sistemáticos, bem como o desenvolvimento da persuasão e de redes de contato; uma vez que a área de Humanidades está ligada os conhecimentos de produção humana, com disciplinas como filosofia, história, antropologia, arte; e as Ciências Sociais, por sua vez, está relacionada aos aspectos sociais das pessoas e dos grupos, que pode incluir disciplinas como: comunicação, administração, ciência política, entre outras. 
Tabela 2. Frequência e percentual cumulativo de cada soma de ponto em cada uma das CCEs

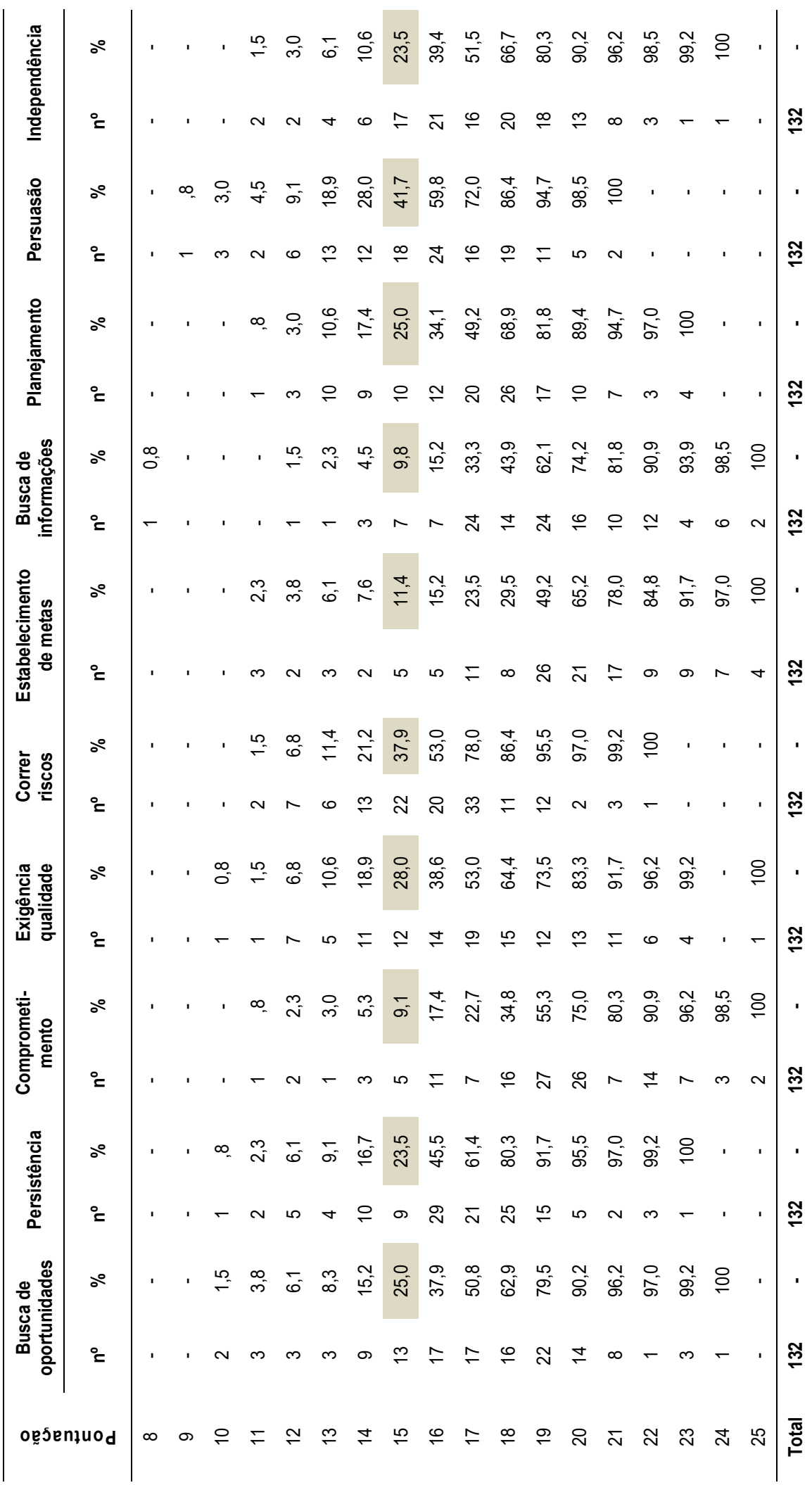

Fonte: Dados da pesquisa. 
No Parecer $n .^{0} 1.362 / 2001$, que apresenta que os currículos sejam flexíveis, que além de atender a área de atuação do profissional, deve dar embasamento filosófico para competência, ênfase na síntese e na transdisciplinaridade, salienta-se a preocupação com a valorização do ser humano e preservação do meio ambiente, integração social e política do profissional, possibilidade de articulação direta com a pós-graduação e forte vinculação entre teoria e prática. Mostra, analisando-se em comparação com as CCEs que estas estariam mais relacionadas às de busca de oportunidades e iniciativa, exigência de qualidade e eficiência, comprometimento e busca de informações.

Já se analisando a Resolução $n^{\circ} 11$, CNE/CES/2002, a mais complexa de todas que dá todo o direcionamento para a formação do estudante de engenharia e consequentemente o que será importante quando da sua atuação como profissional, de certa forma direta ou indiretamente, estaria vinculada a todas as CCEs.

A Resolução $n^{\circ}$ 447, CREA/2000 que aborda especificamente as atribuições do engenheiro ambiental, que é o foco dos estudantes pesquisados, aponta como as principais áreas de atuação destes engenheiros a administração, gestão e ordenamentos ambientais e ao monitoramento e mitigação de impactos ambientais, seus serviços afins e correlatos. Essas atividades estão direcionadas para as CCEs, sob o enfoque deste estudo: busca de oportunidades e iniciativa, exigência de qualidade e eficiência, comprometimento, busca de informações, estabelecimento de metas, planejamento e monitoramento sistemáticos e persuasão e redes de contato.

E por fim a Resolução $n^{\circ}$ 218,CREA/1973, art. $1^{\circ}$ atividades de 1 a 14 e 18, indicam supervisão, coordenação e orientação técnica; estudo, planejamento, projeto e especificação; estudo de viabilidade técnico-econômica; assistência, assessoria e consultoria; direção de obra e serviço técnico; vistoria, perícia, avaliação, arbitramento, laudo e parecer técnico; desempenho de cargo e função técnica; ensino, pesquisa, análise, experimentação, ensaio e divulgação técnica; extensão; elaboração de orçamento; padronização, mensuração e controle de qualidade; execução de obra e serviço técnico; fiscalização de obra e serviço técnico; produção técnica e especializada; condução de trabalho técnico e execução de desenho técnico. Essas atividades profissionais do engenheiro ambiental estariam englobando todas as CCEs apresentadas por McClelland (1972).

Dessa forma, após análise do conteúdo, verificou-se que as duas características que anteriormente apareceram com menos incidência, as quais são: correr riscos calculados e persuasão, são as menos evidenciadas quando comparadas com a regulamentação para atuação do engenheiro, com destaque para correr riscos calculados.

Outras características como, busca de oportunidades e iniciativa, busca de informações e planejamento e monitoramento sistemático, são as que aparecem em maior número de vezes. Isso também vai ao encontro dos resultados quanto à categoria mais desenvolvida pelos acadêmicos, que foi a de planejamento.

Conclui-se, portanto, com base nas análises realizadas que embora as regulamentações das atividades do engenheiro não indiquem explicitamente que este profissional deva ser empreendedor, elas trazem nas suas entrelinhas elementos que fazem despertar ao longo da formação e dos desafios profissionais características empreendedoras que poderão ser aplicadas no decorrer do desenvolvimento de sua carreira, quanto, na implementação de seu próprio negócio. 


\section{CONCLUSÃO}

Constata-se após a realização do estudo que, apesar das exigências atribuídas ao profissional de engenharia não contemplar a capacidade empreendedora explicitamente, as mesmas exigências apresentam características, as quais vão ao encontro com as CCEs. Sendo que, para McClelland as características comportamentais empreendedoras devem ser aplicadas e trabalhadas nos profissionais, das mais diversas áreas de atuação.

Outro ponto importante, que vale ressaltar, é o fato que incide que a educação empreendedora deve ser evidenciada principalmente nas matrizes curriculares das mais variadas instituições de ensino e também aplicados nos mais diversos cursos, visto que a educação empreendedora visa desenvolver um profissional com capacidade criativa, com visão de futuro, com aptidão de visualizar oportunidades que podem vir acontecer nas mais diferentes situações. Cabe dessa forma, que as instituições desenvolvam em seus acadêmicos o espírito empreendedor, ou seja, que o profissional entre para o mercado de trabalho capacitado para enfrentar as adversidades proporcionadas pela sociedade. Ou seja, as universidades têm papel primordial no desenvolvimento educacional dos profissionais, e o desenvolvimento das competências e aptidões que serão aplicadas durante a vida profissional, são em boa parte desenvolvida dentro das instituições de ensino, dessa forma, o ensino do empreendedorismo e o desenvolvimento das CCEs são fundamentais para os futuros profissionais das mais diferentes áreas.

Este assunto tem muito ainda que avançar para formar um engenheiro apto para atuar nas empresas com excelência, ajudando para a inovação nas suas áreas de atuação e no desenvolvimento econômico. É importante as instituições de ensino estarem preparadas para formar um profissional que esteja apto ao mercado de trabalho e seu desenvolvimento profissional.

O objetivo do estudo foi alcançado, pois verificou-se que a maioria das CCEs estão de alguma forma relacionadas às exigências para os cursos de engenharia. Embora o estudo apresente limitações por ter estudado somente um curso de engenharia, os dados são de quatro semestres, mostrando que não é algo específico de uma só turma. Sugere-se que o tema deste estudo seja aprofundado com pesquisas que também analisem as grades curriculares e outros cursos de engenharia.

\section{REFERÊNCIAS}

BARDIN, L. Análise de conteúdo. Lisboa: Edições 70, 2004.

BRASIL. Ministério da Educação. Diretrizes curriculares nacionais dos cursos de engenharia. Parecer $\mathrm{n} .^{\circ} 1.362$, de 12 de dezembro de 2001. Disponível em: http://portal.mec.gov.br/cne/arquivos/pdf/CES1362.pdf. Acesso em: 25 mar. 2017

Plano Nacional de Educação. Lei no 10.172, de 9 de janeiro de 2001. Disponível em: http://www.planalto.gov.br/ccivil_03/leis/leis_2001/l10172.htm. Acesso em: 25 mar. 2017.

Regula o exercício das profissões de Engenheiro, Arquiteto e Engenheiro Agrônomo, e dá outras providências. Lei $n^{\circ}$ 5.194, 24 de dezembro de 1966. Disponível em: http://normativos.confea.org.br/downloads/5194-66.pdf. Acesso em: 25 mar. 2017

CALIENDO, M; FOSSEN, F; KRITIKOS, A. S. Personality characteristics and the decisions to become and stay selfemployed. Small Business Economics. v.42, 4. ed., p. 787-814, 2014. http://link.springer.com/journal/11187

CAMARGO, M. S. G. de. Fundador versos sucessor: estudo comparativo das características comportamentais empreendedoras dos empresários de empresas familiares do município de Chapecó-SC. 2005. 141 f. Dissertação (Mestrado) - Universidade Regional de Blumenau, Programa de Pós-graduação em Administração, 2005.

CONSELHO FEDERAL DE EDUCAÇÃO. Resolução n 48. 27 de abril de 1976. 
CONSELHO FEDERAL DE ENGENHARIA E AGRONOMIA. Decisão Plenária PL 0979/2002. Disponível em: http://normativos.confea.org.br/ementas/visualiza.asp?idEmenta=23707\&idTiposEmentas=\&Numero=\&Anolni=\&AnoFim =\&PalavraChave=\&buscarem. Acesso em: 25 mar. 2017.

Decisão Plenária PL1701/2008: Disponível em:

http://normativos.confea.org.br/ementas/visualiza.asp?idEmenta=41134\&Numero. Acesso em: 25 mar. 2017.

Decisão Plenária PL 0464/2007. Disponível em:

http://normativos.confea.org.br/ementas/imprimir.asp?idEmenta=38587. Acesso em: 25 mar. 2017.

Regulamenta a atribuição de títulos profissionais, atividades, competências e caracterização do âmbito de atuação dos profissionais inseridos no Sistema Confea/Crea, para efeito de fiscalização do exercício profissional. Resolução $n^{\circ}$ 1.010, 22 de agosto de 2005. Disponível em: http://normativos.confea.org.br/ementas/visualiza.asp?idEmenta=550. Acesso em: 25 mar. 2017.

Decisão Plenária PL 3723/2003. Disponível em:

http://normativos.confea.org.br/ementas/imprimir.asp?idEmenta=33028\&idTiposEmentas=\&Numero=\&Anolni=\&AnoFim $=\&$ PalavraChave=\&buscarem $=$. Acesso em: 25 mar. 2017.

Resolução $n^{\circ}$ 447, 22 set. 2000. Disponível em:

http://normativos.confea.org.br/ementas/visualiza.asp?idEmenta=495. Acesso em: 09 mar. 2017

Discrimina atividades das diferentes modalidades profissionais da Engenharia, Arquitetura e Agroonomia. Resolução $n^{\circ} 218,29$ de junho de 1973. Disponível em: http://normativos.confea.org.br/ementas/visualiza.asp?idEmenta=266. Acesso em: 25 mar. 2017.

CONSELHO NACIONAL DE EDUCAÇÃO. Câmara de Educação Superior. Diretrizes Curriculares Nacionais do Curso de Graduação em Engenharia. Resolução CNE/CES 11, 11 de março de 2002. Disponível em: http://portal.mec.gov.br/cne/arquivos/pdf/CES112002.pdf. Acesso em: 25 mar. 2017

DIAS, T. R. F. V; SOUZA NETO, S. P. de; BOAS, A. A. V. Características Comportamentais Empreendedoras Relevantes: Estudo de Caso dos Ganhadores do Prêmio TOP Empresarial 2007. Anais do VI Encontro de estudos sobre empreendedorismo. Recife: 2010. Disponível em: http://www.anegepe.org.br/edicoesanteriores/recife/EMP103.pdf. Acesso em: 16 mar. 2017.

DOLABELA, F. C. Oficina do empreendedor: a metodologia do ensino que ajuda a transformar conhecimento em riqueza. Rio de Janeiro: Sextante, 2008.

FILION, L. J. Empreendedorismo: empreendedores e proprietários - gerentes de pequenos negócios. Revista de Administração da Universidade de São Paulo. São Paulo, v.34, n.2, p.05 - 28, abril/ junho, 1999. Disponível em: 200.232.30.99/download.asp?file=3402005.pdf. Acesso em: 16 mar. 2017

GIL, A. C. Métodos e técnicas de pesquisa social. 6. ed. São Paulo: Atlas, 2008.

Como elaborar projetos de pesquisa. 4. ed. São Paulo: Atlas, 2002.

HISRICH, R. D.; PETERS, M. P.; SHEPHERD, D. A. Empreendedorismo. 7. ed. São Paulo: Bookman, 2009.

HOLIENKA, M.; HOLIENKOVÁ, J.; GÁL, P. Intrepreneurial characteristics of students in different fields of study: a view from entrepreneurship education perspective. Acta Universitatis Agriculturae et Silviculturae Mendelianae Brunensis. v.63, n. 6, 2015.

LEE, J.; SHIM, K.; LEE, H. Entrepreneurial characteristics: a systematic literature review. Pacific Asia Conference on Information Systems (PACIS), 2016. Disponível em:

<http://aisel.aisnet.org/cgi/viewcontent.cgi?article=1087\&context=pacis2016>. Acesso em: 10 mar. 2016.

MACHADO, F. Atribuições profissionais do Engenheiro Ambiental. Conselho Regional de Engenharia e Arquitetura de Santa Catarina. 13 nov. 2009. Disponível em: http://www.crea-sc.org.br/portal/index.php?cmd=artigosdetalhe\&id=610\#.WMCIfPnyvlU. Acesso em: 15 mar. 2017

McCLELLAND, David Clarence. A sociedade competitiva: realização e progresso social. Rio de Janeiro: Expressão e Cultura, 1972.

RICHARDSON, R. J. et al. Pesquisa social: métodos e técnicas. 3. ed. São Paulo: Atlas, 2008. 